\title{
FORESIGHTING TECHNOLOGICAL AND INNOVATIVE DEVELOPMENT OF BELARUS
}

\author{
Mikalai Zianchuk \\ School of Business of Belarusian State University, Minsk, Belarus \\ Irina Saltanova \\ Belarusian Institute of System Analysis, Department of Analysis of \\ Technological Trends and Foresight, Minsk, Belarus \\ CMESTE \\ JEL Category: 014, 031, 032
}

\begin{abstract}
This paper focuses on the foresight technological and innovative development of the Republic of Belarus. The main objective of the paper is to postulate the importance of foresight innovation for building a competitive economy. Approaches to conducting scientific and technological forecasting in the Republic of Belarus at different periods are described in this paper. World experience in conducting technological forecasting shows that most countries carry out systemic foresight studies to predict scientific and technological progress. Formation of the next Comprehensive forecast of scientific and technological progress for the Republic of Belarus for 2021-2025 and for the period until 2040 (CF 2025) was carried out in the period 2018-2019 in the Republic of Belarus. The methodology was based on the global experience of foresight research, which was adapted to account for the specifics of the functioning of the economy of the Republic of Belarus. CF 2025 makes possible: 1) to identify main promising areas of scientific and technical development of the Republic of Belarus; 2) to identify product groups and breakthrough technologies, and 3) to determine a shortlist of promising innovative products for the Republic of Belarus. The paper describes the basics of the methodology and the main stages of foresight and describes the possibilities of using the results of foresight for planning the implementation of various scenarios of economic growth and achieving sustainable development goals.
\end{abstract}

Keywords: comprehensive prognosis, foresight, scientific and technological development, experts, objects of foresight, world trends.

\section{INTRODUCTION}

Management of innovative development is based on the prediction of the emergence of innovations both in the field of technology and in the field of consumer goods, analysis of possible alternatives

Address of the corresponding author:

Mikalai Zianchuk

莑=; ZenchukNF@mail.ru for technological and innovative development, and comparison of the economic potential of these alternatives.

The Republic of Belarus is among the countries with significant scientific potential, but not having a sufficient raw material base. In these conditions, the role of the use of intellectual resources and scientific and technological potential is growing sharply. 
A reasonable choice of medium-term and longterm priorities for scientific, technological, and innovative development allows us to increase the competitive potential of the national economy by increasing its comparative advantages in science, education, and high technologies and, on this basis, use new sources of economic growth.

By applying forecasting tools to select further priorities for scientific and technological development, the country gets high chances to enter the emerging world high-tech markets and to build a competitive economy.

In the period 2018-2019 in the Republic of Belarus work was carried out to formulate the next Comprehensive Forecast of Scientific and Technical Progress for the Republic of Belarus for 2021-2025 and for the period until 2040. This paper describes the basics of the methodology and the main stages of this study, as well as the possibilities of using forecasting results for planning the implementation of various scenarios of economic growth and for achieving sustainable development goals.

\section{EXPERIENCE OF TECHNOLOGI-}

\section{CAL FORECASTING AT THE NATIONAL LEVEL}

Currently, the world forecasting practice covers a variety of approaches, which is the result of constantly changing economic conditions and of the opportunities available to researchers.

All countries that steer their economies along the path of innovation invariably turn to forecast in the form of systemic foresight studies. Foresight is a system of methods for expert evaluation of strategic areas of socio-economic and innovative development, for identifying technological breakthroughs that can affect the economy and society in the medium and long term.

At present, there is no single definition of foresight as a forecasting method. Nevertheless, several basic features are characteristic of foresight as a form of research:

- within the framework of the foresight, an assessment of the possible prospects for innovative development related to the progress of science and technology is carried out, possible technological horizons are outlined.
- foresight always implies the participation of many experts from all fields of activity, in a varying degree related to the subject of a specific foresight project.

- when conducting foresight research, a set of interrelated tasks of an economic, scientific, and technological nature is solved.

Each country chooses its foresight research structure considering national characteristics: goals of the government's socio-economic policy, key problems of its development, tasks of ensuring national defense and security. Features of the country affect the choice of areas of innovative development, the choice of sources of information reflecting the state of scientific, technological, and industrial activity in the country, as well as the choice of sources reflecting global scientific and technological trends. But the foresight platform is the same for everyone: studying current and future challenges arising under the influence of global changes, identifying key technologies, developing a strategy for the future development of the country's economy.

Foresight is used in many countries of the world, and not only in developed, but also in developing. Rich experience in this area has been accumulated in Japan, Great Britain, and Germany. Studies are conducted regularly in China, South Korea, South Africa, and Latin America. The number of studies in the world today is measured in the thousands. For example, the European Foresight Monitoring Network (EFMN) program covers more than 2,000 different studies conducted at the international level, at the level of countries, regions, industries, corporations.

Among the former Soviet countries, the Russian Federation and Kazakhstan have experience in conducting foresight research at the national level.

In the Russian Federation, the first major project at the national level was the long-term foresight of the scientific and technological development of Russia for the period until 2025, initiated in 2007 by the Ministry of Education and Science of Russia (Chulok, 2009). This document includes three major blocks:

- macroeconomic forecast of the Russian economy.

- prediction of the sphere of science and technology (in priority areas). 
- industry foresight, the purpose of which is the working-out of technological development alternatives for the most important sectors of the economy.

In the next stage of scientific and technological foresight (2009-2010), the experience of foreign and international forecasts in the socio-economic and scientific-technological fields was generalized. Based on this experience, estimates were made of the future global economy and individual large world markets, considering the expected consequences of the financial and economic crisis (Blinkin, M.Y., et al., 2014).

The obtained results formed the basis of the macroeconomic forecast of the Russian economy, as well as the variant foresight of the technological development of many sectors. The project identified a group of promising technologies and products that meet the priorities of the technological modernization of the country.

In 2013 the development of foresight for the scientific and technological development of the Russian Federation until 2030 was completed. The purpose of this foresight was to identify the most promising areas of science and technology for Russia that would provide a significant contribution to solving socio-economic problems and realizing the country's competitive advantages (Blinkin, M.Y., et al., 2014).

As part of the work on this forecast, trends were identified that have the greatest impact on the field of science and technology, and the challenges they generate for the long-term development of the economy, science, and society in global and national contexts.

As a result, 7 priority areas for the development of science and technology were identified: "Information and communication technologies"; "Biotechnology"; "Medicine and healthcare"; "New materials and nanotechnology"; "Rational nature management"; "Transport and space systems"; "Energy Efficiency and Energy Saving".

The following activities were implemented for each of these priority areas:

- threats and windows of opportunity were identified for Russia based on the identified trends.

- promising markets, product groups, and potential areas of demand for Russian innovative technologies and developments have been identified.

- a detailed description of priority thematic areas for the development of science and technology has been compiled and more than 1000 priority tasks of research and development have been formulated, the implementation of which is necessary for the appearance of the considered groups of innovative products and services.

- the state of domestic research was assessed in these areas ("white spots" were identified, as well as parity and leadership zones, which could become the basis for integration into international alliances and positioning Russia as a center of global technological development).

- recommendations have been prepared to aim at enhancing the use of forecast results in the practice of scientific, technical, and innovation policy, including in the formation, adjustment, and implementation of state programs of the Russian Federation, including federal targeted programs of scientific and technological orientation.

The experience of conducting foresight research in the Russian Federation as a national program for forecasting the country's innovative development with the development of conclusions and recommendations of national importance seems to us to be a good example of a scientifically based comprehensive approach to solving such problems.

\section{METHODOLOGY OF THE TECHNOLOGICAL FORESIGHT OF BELARUS}

A system document that determines the procedure for developing the forecast of scientific and technological development in the Republic of Belarus is Decree of the Council of Ministers of the Republic of Belarus dated June 17, 1998 No. 945 "On the organization of developing a comprehensive forecast of scientific and technological progress of the Republic of Belarus and determining priority areas of scientific and technical activity in the republic".

A comprehensive forecast of scientific and technological progress (CF STP), along with forecasts of socio-economic development, serves 
as the basis for determining the system of priorities for scientific, scientific-technical, and innovative activities. Forecasting of technological development is understood as the prediction of development trends and the future state of engineering and technology in a certain field, made by scientifically sound methods based on the analysis and evaluation of previous stages of the development of engineering and technology and their current state (Law, 2012).

The state customer for the development of the CF STP of the Republic of Belarus is the State Committee for Science and Technology of the Republic of Belarus (SCST).

CF STP of the Republic of Belarus for the period 1998-2010 was developed by the State Institute of Economics of the National Academy of Sciences of Belarus. This organization has developed three CF STPs of the Republic of Belarus.

The development of the CF STP of the Republic of Belarus for 2016-2020 and for the period up to 2030 was carried out by the State Institute "Center for System Analysis and Strategic Studies of the National Academy of Sciences of Belarus", and for 2021-2025, by the State Institute "Belarusian Institute of System analysis and information support of the scientific and technical sphere".

The Institute of Economics of the National Academy of Sciences of the Republic of determined the following sections of the CF STP:

1. Analysis of global trends in scientific and technological development.

2. Analysis of the state of the scientific and technological potential of the Republic of Belarus.

3. Forecast of scientific and technological progress in the sectors of the Republic of Belarus for the selected period.

4. Forecast of scientific and technological progress in the regions of the Republic of Belarus for the selected period.

The main emphasis was placed on forecasting scientific and technological development in the context of existing branches of the economy of the Republic of Belarus.

The structure of the CF STP developed by the State Institution "Center for System Analysis and Strategic Studies of the National Academy of
Sciences of Belarus" included the following sections:

1. Forecast of economic development as the target dominant of scientific and technological development.

2. Priorities of scientific and technological development of the Republic of Belarus for 2016-2020 in the context of international comparisons.

3. The most important directions for the implementation of priorities in the system "science - technology - innovative economy" for the period until 2030.

4. Conditions and policies for the implementation of the forecast.

5. Projected results of the interaction of science and economics.

The main emphasis was placed on forecasting scientific and technological development in the context of the most important areas for the implementation of priorities in the system "science - technology - innovative economy".

In terms of the most important directions for the implementation of priorities in the system "science - technology - innovative economy" for the period until 2030, the following branches were considered: biotechnologies for the agro-industrial complex and medicine; aerospace technology; information and communication technologies; modernization and intellectualization of existing industries (machine-, instrument- and machine tool building, energy, chemical, and petrochemical production); logistics and container technology in transport; regions and territories; environmental imperative as a key factor in sustainable development.

The methodology for the development of the above-mentioned CF STP was based on the following method of collecting and processing source data. The developers of the CF STP through state bodies (ministries and concerns), supervising the relevant branches of the economy, sent out a request about the state of scientific and technological progress and innovative activity in these branches and the prospects for the development of these branches. This request descended along the hierarchy of management to lower levels, that is, to specific managers and specialists "on the ground" - at enterprises and in research units. 
Managers and field specialists, in this case, acted like experts. They formed information about the state of scientific and technological progress and innovation at their enterprise and the branch.

Further, this data was transferred up the management hierarchy, to higher levels. In this case, their partial generalization could occur. From government bodies, the data collected in this way was transmitted to the developers of the $\mathrm{CF}$ STP in response to their request.

At the end of the work, the developers of the CF STP performed the final systematization and adjustment of the collected data, bringing them into a specific format.

Proposals on the structure and content of the CF STP for 2021-2025 and the period until 2040 (hereinafter CF 2025) were developed at the Belarusian Institute of System Analysis and Information Support for the Scientific and Technical Sphere in 2018. The methodology was based on the global experience of foresight research, which was adapted considering the characteristics of the functioning of the economy of the Republic of Belarus. An impact on the methodology of the CF STP was exerted by the experience of foresight in the scientific and technological development of Russia 2030 (Hochberg, et al., 2016).

The purpose of CF 2025 was to obtain scientifically-based ideas about possible alternatives for scientific, technological, and innovative development of the Republic of Belarus in the medium term ( 5 years) and the long term in the context of world scientific and technological development.

The prediction was carried out in the context of the selected promising areas of scientific and technological development, and for each of the areas - in the context of sectors of the economy of the Republic of Belarus.

The initial list of promising areas of scientific and technological development was formed by experts based on global trends and the provisions of the Strategy "Science and Technology: 2018-2040" (Strategy, 2017). It included such areas as information and communication technologies; robotization and mechatronics; the energy of the future; space systems, unmanned technical systems; nano industry; bio-industry; additive technology; compositional and "smart" materials; ecology and environmental management.

Each of the promising areas was considered in the context of 14 major sectors of the economy, the development of which is largely determined by the main economic trends in the country: industry (except petrochemical), light and food; petrochemical industry; light industry; food industry; agriculture; transport and communications; architecture and construction; communication and informatization; power engineering; the science; education; healthcare; forestry; natural resources and environmental protection.

The intersection of the corresponding area of scientific and technological development and the corresponding sector of the economy was considered as a foresight area. Within each forecasting area, specific foresight objects stood out: promising innovative technologies, product groups, and goods.

The development of CF 2025 included the following steps:

- compiling a list of foresight objects.

- obtaining the values of the parameters of foresight objects.

- processing parameters of foresight objects.

To develop lists of forecasting objects the work of experts was organized based on the Delphi method. The Delphi method involves conducting questionnaires of experts (direct debates of experts are excluded) and making further multiple adjustments of the results based on familiarizing each expert with the opinions of other experts.

The work of experts was carried out as part of expert groups that were formed by sectors of the economy. The expert community for the research included more than 130 representatives of various organizations of the national educational institutions, research institutes, industrial enterprises, innovative companies, marketing organizations, government agencies.

As a result of 3 stages of Delphi, information was obtained on 302 technologies, goods and services, the appearance of which on the markets is expected in the period from 2021 to 2025 , and 338 foresight objects, the appearance of which in the markets is expected in the period until 2040. 
Based on the numerical analysis of a large amount of data for each technology, product, and service, the following groups of parameters were determined: global trends in publications and patents; global market capacity; the state of the infrastructure of the Republic of Belarus.

The first two groups of parameters characterized the demand for the foresight object for the foresight period. The third group of parameters characterized the feasibility of the foresight object in the conditions of the Republic of Belarus.

Trends in international and domestic publications and patents were obtained based on analysis of publication databases: Scopus, Web of Science; patent bases: Eurasian Patent Organization, European Patent Office, World Intellectual Property Organization, Rospatent, National Intellectual Property Center of the Republic of Belarus.

The capacity of the world market for each foresight object was determined based on marketing research and analysis of various sources including the database of the World Economic Outlook, the International Monetary Fund, data from the World Bank, OECD, WHO, the UN Department of Economic and Social Affairs and many others, depending from the specifics of industries.

The state of the infrastructure of the Republic of Belarus for each foresight object was evaluated by a combination of the following parameters:

- the state of production capacities (whether a forecasting object is currently being produced; if it is being produced, then at what enterprises; can a foresight object be produced at existing capacities).

- the number of research and development, experimental and technological works (R\&D) registered in the State Register of R\&D for 5 years, taking into account information about the degree of readiness of the foresight object (idea, concept; experimental model; prototype, pilot batch; small-scale production);

- the number of domestic scientific publications.

- the number of patents registered in patent databases and registers of the National Center for Intellectual Property.

- information about personnel potential.

Based on the obtained values of the parameters of foresight objects, the demand and feasibility indices were calculated. Based on the additive convolution of the normalized values of these parameters, the prospectivity index of each technology, product, and service was calculated.

The values of this index were used in compiling corresponding ratings, according to the foresight as a whole and for each of the economic sectors (Zianchuk, et al., 2018).

\section{PLANNING THE ECONOMIC DEVELOPMENT OF BELARUS BASED ON TECHNOLOGICAL FORECASTING}

CF 2025 is used as the basis for the selection of strategic priorities for the development of the Republic of Belarus.

In the course of analysis and evaluation of the areas of scientific and technological progress, on one hand, the shortcomings of certain previously formulated areas of scientific and technological progress were revealed, and the other hand, the need of many traditional areas of scientific and technological progress in new tools and technologies are revealed.

Based on the results of the development of CF 2025 new priority areas of scientific, scientifictechnical, and innovative activity in the Republic of Belarus have been formulated, balanced in terms of prospects (based on the analysis of the rating of technologies, goods and forecast services).

1. information and communication, aerospace, and interdisciplinary technologies.

2. energy, ecology, and environmental management.

3. innovative materials.

4. bioengineering, chemical, and medical technologies.

5. agro-industrial and food technologies.

6. mechanical engineering, photonics, micro-, opto- and microwave electronics.

A comprehensive forecast of scientific and technological progress along with forecasts of socio-economic development serves as the basis for determining the priority system of scientific, technological, and innovative activities of the Republic of Belarus. The foresight results are used in the development of the National Strategy for Sustainable Development of the Republic of 
Belarus and other documents for planning economic development.

The developed foresight provides a scenario approach to managing economic growth. Prospects for the development of innovative technologies, product groups, and products are presented in three options for the development of the country's economy: pessimistic, balanced, and optimistic. Based on the number of resources available for each scenario, it is possible to determine which technologies, product groups and innovative products are subject to priority investment, and to which level (Shumilin, et al., 2019).

Based on the foresight, it is possible to form some significant large-scale projects (in the field of healthcare, robotics, etc.) focused on the production of goods in the Republic of Belarus that correspond to world trends in scientific and technological development, taking into account the prospects of the sales market (Zianchuk, et al., 2019).

The implementation of such "projects of the future" will promote the development of technologies, creating goods and services with significant competitive advantages in existing markets, and creating the potential for forming new market niches for domestic products.

\section{CONCLUSIONS}

One of the most important tasks for the Republic of Belarus on the path of innovative development is the activation of consistent scientific, scientifictechnical, and innovative activities in all areas of the economy. The results of these activities should be expressed in the development of new technologies, the creation of new industries, and the strengthening of the country's position in world markets. CF 2025 is one of the most important components of solving this problem.

During the development of CF 2025, systematic work was carried out related to the identification of the most promising innovative technologies, product groups, goods, or services for Belarus.

When developing CF 2025, the following papers were considered: The Concept of National Security of the Republic of Belarus, the National Strategy for Sustainable Social and Economic Development of the Republic of Belarus, and the Strategy "Science and Technology: 2018-2040".

When developing the foresight, the following were used: industry sector plans and development strategies of interested government bodies and organizations subordinate to the Government of the Republic of Belarus; exchange of experience results and expert consulting support of leading international foresight structures; forecast of scientific and technological development of Russia: 2030; American Leading Production Strategy (USA); the main trends of 2019 according to the Massachusetts Institute of Technology; the publication of the National Intelligence Council (USA) "Global Trends 2030: Alternative Worlds"; the main trends in the development of new technologies according to Gartner; reviews of the innovative development of various countries prepared by the United Nations Economic Commission for Europe.

The developed CF 2025 could become the basis of the national system of technological foresight of the Republic of Belarus, which is currently at the initial stage of formation.

\section{WORKS CITED}

Blinkin, M.Y., \& Gokhberg, L.M. (2014). Forecast of scientific and technological development of Russia: 2030. Transport and space systems Moscow : Ministry of Education and Science of the Russian Federation, National Research University Higher School of Economics, $-40 \mathrm{p}$.

Chulok, A.A. (2009). Forecast of the prospects of scientific and technological development of key sectors of the Russian economy. Forsyth Magazine, 3(11), 30-36.

Hochberg, L.M., Sokolov, A.V., Mikov, N.S., Gutaruk, E.V., et al. (2016). Global technology trends. Moscow : Nat. researched University "Higher School of Economics". pp. 192.

Law (2012). On state innovation policy and innovation in the Republic of Belarus: Law of the Republic of Belarus dated July 10, 2012, No. 425-3. Minsk : Consultant plus. Belarus. Technology, LLC "YurSpektr". 
Shumilin, A., Scherbakov, S., \& Shlychkov, S. (2019). On the results of the Comprehensive Forecast of Scientific and Technical Progress. Science and Innovations, 12 (202), 31-40.

Strategy (2017). Strategy Science and Technology: 2018-2040. Minsk : Nat. Academy of Sciences of Belarus. pp. 40.

Zianchuk, M.F., Saltanova, I.V., \& Shlychkov, S.V. (2018). Methodological basis for the development of a comprehensive forecast of scientific and technological progress of the Republic of Belarus. News of science and technology, 4(47), 10-18.

Zianchuk, M.F., \& Saltanova, I.V. (2019, Sep 20-21). About the possibility of implementing innovative projects based on domestic developments and technologies. System 'science - technology innovation': methodology, experience, prospects: Materials Intern. scientific-practical conf. Minsk: Center for System Analysis and Strategic Studies of the NAS of Belarus, pp. - 500 .

Received for publication: $\quad 10.03 .2020$

Revision received: $\quad 08.05 .2020$

Accepted for publication: $\quad 01.07 .2020$

\section{How to cite this article?}

Style - APA Sixth Edition:

Zianchuk, M., \& Saltanova, I. (2020, July 15). Foresighting technological and innovative development of Belarus. (Z. Cekerevac, Ed.) MEST Journal, 8(2), 192-199. doi:10.12709/mest.08.08.02.22

Style - Chicago Sixteenth Edition:

Zianchuk, Mikalai, and Irina Saltanova. 2020. "Foresighting technological and innovative development of Belarus." Edited by Zoran Cekerevac. MEST Journal (MESTE) 8 (2): 192-199. doi:10.12709/mest.08.08.02.22.

Style - GOST Name Sort:

Zianchuk Mikalai and Saltanova Irina Foresighting technological and innovative development of Belarus [Journal] // MEST Journal / ed. Cekerevac Zoran. - Belgrade - Toronto : MESTE, July 15, 2020. - 2 : Vol. 8. - pp. 192-199.

Style - Harvard Anglia:

Zianchuk, M. \& Saltanova, I., 2020. Foresighting technological and innovative development of Belarus. MEST Journal, 15 July, 8(2), pp. 192-199.

Style - ISO 690 Numerical Reference:

Foresighting technological and innovative development of Belarus. Zianchuk, Mikalai and Saltanova, Irina. [ed.] Zoran Cekerevac. 2, Belgrade - Toronto : MESTE, July 15, 2020, MEST Journal, Vol. 8, pp. 192-199. 